\title{
CÉLULA DE MANUFATURA APLICADA A MONTAGEM DE SUB CONJUNTOS EM MATERIAL COMPÓSITO PARA ÔNIBUS
}

\section{MANUFACTURING CELL APPLIED TO COMPOSITE MATERIALS ASSEMBLY INTO BUS MANUFACTURING COMPANY}

\author{
Deandro Rech ${ }^{1}$, Carlos Alberto Costa², Marcos Alexandre Luciano3,"
}

\section{RESUMO}

\begin{abstract}
Este artigo propõe a implementação de um layout celular em um setor de acabamento e montagem de componentes compósitos em empresa fabricante de ônibus, visando elevar o aproveitamento operacional com redução das perdas e melhor aproveitamento do espaço físico. Para realização da proposta do trabalho, foi projetada uma célula de manufatura piloto, com base na formação da família de peças com processos semelhantes, com a análise dos fluxos de produção e o acompanhamento no aproveitamento dos recursos utilizados para o atendimento das demandas de peça. A partir do estudo das informações coletadas foi possível verificar o balanceamento das tarefas por meio do diagrama de precedência e método de utilização incremental. Neste sentido foram atendidas as expectativas para a proposta implementada em relação ao arranjo anterior, com destaque na redução das perdas por movimentação e ociosidade, consequentemente elevação nos tempos produtivos.
\end{abstract}

Palavras-chave: Arranjos Físicos, Manufatura Celular, Materiais Compósitos, Montagem de Ônibus.

\begin{abstract}
This paper proposes the implementation of a cellular layout in a sector of finishing and assembly of composite components in bus manufacturing company, in order to raise the utilization with reduction of operating losses and better use of the physical space. For achievement of the proposed work, designed a pilot manufacturing cell based on the formation of the family of parts with similar processes, with the production flow analysis and monitoring in the use of resources used to meet the demands of the play. From the study of the information collected was unable to check the balance of tasks through the precedence diagram and use incremental method. In this sense the expectations were met to the proposal implemented in relation to the previous arrangement, with emphasis on reduction of losses due to handling and idleness, consequently high productive times.
\end{abstract}

Keywords: Physical Arrangements, Cellular Manufacturing, Composite Materials, Buses Assembly.

${ }_{1}^{1}$ Marcopolo SA. Caxias do Sul, Brasil - deandro. orcid.org/0000-0003-1386-2200, rech@marcopolo.com.br

${ }^{2}$ Universidade de Caxias do Sul, Centro de Ciências Exatas e Tecnologia, Programa de Pós-Graduação em Engenharia Mecânica. Caxias do Sul, Brasil. orcid.org/0000-0001-5623-8411, cacosta@ucs.br.

${ }^{3}$ Universidade de Caxias do Sul, Centro de Ciências Exatas e Tecnologia, Programa de Pós-Graduação em Engenharia Mecânica. Caxias do Sul, Brasil. orcid.org/0000-0003-0668-1559 


\section{INTRODUÇÃO}

O rearranjo da manufatura e a aplicação de técnicas para produção com redução das perdas, estimulam o aperfeiçoamento organizacional com uma nova estrutura, estratégia e cultura de operação (Smeds,1994). Seguindo esta linha, Villar (2004) caracteriza o arranjo físico pelo potencial em aumentar a moral e satisfação no trabalho; economizar o espaço físico; aumentar a utilização dos equipamentos, mão de obra e serviços.

Para Urnau e Domingues (1996) a evolução na organização da produção é resultado da necessidade das empresas em atender as exigências do mercado, formando um panorama de elevação na produtividade e flexibilidade. A capacidade em proporcionar respostas rápidas às demandas e a produção em pequenos lotes, destacou o layout celular como uma solução para diversificação dos produtos além de aumentar a competitividade das empresas (Olivério,1985). No layout celular os recursos são direcionados conforme as particularidades das famílias de peças com o intuito de trabalhar com o mínimo de movimentação de materiais e estoques intermediários (Arruda, 1994). Conforme Oliveira (2007) a célula auxilia na redução do retrabalho pela proximidade das operações e na visibilidade para identificação de longos setups e máquinas gargalos.

Conforme Yasuda e Yin (2001), a formação do arranjo celular pode acontecer com a aplicação da filosofia da Tecnologia de Grupo, onde as diferentes peças e produtos são agrupados pela semelhança de projeto e/ou processo demanufatura. Um aspecto relevante na formação das famílias de partes com a tecnologia de grupos é citado por Conceição (2005). Segundo este autor o ideal no agrupamento de peças seria a independência no processamento e a inexistência de relacionamento entre uma célula com outra, assim a alternativa é alocar ao máximo os recursos de forma a minimizar os deslocamentos intercelulares.

A configuração de ônibus do tipo rodoviários, que são usados para longas viagens, são fortemente dependentes das especificações das empresas de transporte, i.e. clientes. Dependendo do cliente, os ônibus poderão diferentes características como pisos simples ou duplos (double decker), escadas retas ou curvas, e banheiros na frente, meio ou atrás do veículo, e outras variações. Isso faz com que esses subconjuntos (escadas e banheiros, por exemplo), sejam produzidos de forma customizada para cada carro produzido. Pelas características dos materiais utilizados nesses tipos de subconjuntos, como fibras e termofixos, os mesmos são fabricados em unidades separadas da linha de montagem dos ônibus. Devido a natureza da indústria automobilística o seu sistema de produção normalmente é definido em forma de linha, e isso é replicado para a maior parte dos setores que produzem os subconjuntos a serem montados no produto final. Adicionalmente, devido as características de conformação de materiais termofixos, tais tipos de setores se organização num formato de layout por processo. Contudo, como os subconjuntos em questão possuem um alto nível de personalização, observa-se que a estruturação de layout para esses tipos de produtos pode ganhar maior eficiência e eficácia, fazendo uso de um arranjo do tipo celular, sendo essa a proposta desse trabalho.

Desta forma, os subconjuntos desse setor, possuem uma sequência definida de etapas, indiferente se o produto trata-se de uma escada ou um banheiro, sendo que a cada nova ordem de produção todos os passos são seguidos. Isso faz com que o espaço para a linha de produção seja grande, além da necessidade de se dispor que trabalhadores que saibam os detalhes dos diferentes tipos de subconjuntos. Adicionalmente, os tempos e distâncias dispensados com deslocamento dos operadores e das peças é considerado alto dentro do 
tempo total de produção, além de uma deficiência no controle das atividades dos trabalhares envolvidos.

Neste contexto, este trabalho apresenta um estudo sobre o desenvolvimento e a implantação de um layout do tipo celular para uma planta responsável pelo processamento de componentes poliméricos. Em seguida realiza-se uma pesquisa para o entendimento das diferentes características de layouts e identificação da melhor proposta vinculada ao modelo de produção. A partir dos dados do ambiente produtivo e do modelo de produção desejado propõe-se o layout adequado e se avalia sua implementação.

\section{ARRANJOS FÍSICOS}

Conforme Slack et al. (2009) a definição do arranjo físico consiste em decidir onde colocar as instalações, máquinas equipamentos e mão de obra, de forma que, exista a integração entre as áreas produtivas no ambiente interno da empresa. Villar (2004) aborda alguns princípios fundamentais inerentes ao projeto de arranjos físicos, como a integração, redução das distâncias e fluxo contínuo das operações, considerando três dimensões: satisfação, segurança e flexibilidade.

Durante o planejamento do arranjo físico é indispensável atender a sequência lógica entre as atividades, como meta evitar a geração de perdas e prever alterações futuras para viabilizar sua implementação (Slack et al., 2009). Para Leite e Diniz (2006) a alteração do layout está atrelada a melhoria no desempenho do negócio da empresa e ao processo de manufatura com suas restrições. Nesta direção, a diminuição das estagnações nos materiais entre as etapas do processo, resulta no ganho em custos pela redução nas perdas de manufatura, tempo de atravessamento e elevação no valor agregado ao produto final, alem de proporcionar a qualidade assegurada (Alvarez e Antunes JR., 2008).

Existem diversas maneiras de se organizar o espaço físico (Slack, 2009; Correa e Correa, 2000; Sampaio, 2007), cada qual atendendo preferencialmente necessidades produtivas em função das demandas, flexibilidades e configurações de produtos. Entretanto as empresas atualmente adotam layouts mistos, geralmente originados de modelos tradicionais conforme os descritos a seguir.

O arranjo físico posicional é caracterizado pela dimensão das peças produzidas, devido ao peso e tamanho, o produto permanece estático durante a agregação de materiais, máquinas e pessoas (Oliverio, 1985). O arranjo físico funcional, também conhecido por processo, abrange uma grande variedade de produtos em pequenos lotes o que propicia flexibilidade nas etapas de manufatura (Black, 1998). Neste sentido, Oliverio (1985) afirma que o agrupamento das operações com necessidades similares devem estar localizadas próximas para favorecer a movimentação entre os recursos transformadores, ao contrário elevaria os tempos despendidos em movimentações e esperas. O arranjo físico por produto, conforme Black (2001) é uma estrutura de produção distribuída pela sequência de operação realizada 
no produto, para atender uma demanda de fabricação alta de um único item no menor tempo possível.

Diferente do arranjo em linha, Black (1991) destaca que o arranjo físico celular é uma alternativa para se flexibilizar a produção, alem de existirem todos os processos para concluir a produção do determinado modelo de peça. Este modelo é caracterizado fisicamente pela disposição das máquinas dentro de espaço especifico para transformação, onde ao contrário do arranjo por processo, observa-se um alto fluxo no interior da célula.

\section{MANUFATURA CELULAR}

O objetivo da manufatura celular está na flexibilidade operacional para atender a fabricação das diferentes famílias de peças organizadas no layout além de permitir o processamento dos materiais entre as tarefas onde um número reduzido de operadores possa acompanhar todas as fases de produção (Lorini, 1993). Quanto à forma de organização e integração dos equipamentos na manufatura celular podem ser largas, pequenas, seriadas, automáticas ou manuais sendo orientadas para peças ou máquinas (Askin e Goldenberg, 2002; Secchi e Camuffo, 2016).

Para Silveira (1994) as células com transporte manual podem processar um conjunto de componentes ou peças prontas sem auxílio de mecanismos automático para movimentação entre os postos de operação. Lorini (1993) defende o formato de célula em "U" para pequenos grupos de peças, de maneira que os materiais e componentes entrem e saiam pelo mesmo lado, assim facilitando as movimentações. Conforme Miltenburg (2001) o layout em forma de "U" é amplamente utilizado para aprimorar a qualidade e reduzir o lead-time, além de ser uma importante ferramenta onde existem problemas com elevado absenteísmo. Schonberger (1993) reforça afirmando a possibilidade do mesmo operador atuar em duas atividades distintas conforme o balanceamento e a disponibilidade funcional.

Assim como Lorini (1993), Silveira (1994) destaca que em relação à operação, é fundamental levar em consideração a relação entre recursos necessários e a distribuição das cargas de trabalho (número de peças e máquinas por grupo). O conhecimento dos tempos de processo das peças auxilia na definição das famílias em cada célula e na realocação caso alguma peça precise ser produzida fora da célula devido sua complexidade, como alternativa pode ser optado a terceirização nos casos de lotes pequenos.

Um dos critérios para extrair bons resultados na manufatura celular de acordo com Osbayrak e Bell (2003) está no agrupamento constante das famílias de peças e na sua programação diária de produção. Sendo assim, observa-se experimentalmente uma forte influência do tamanho no lote em processamento para o desempenho do layout, onde está vinculado o fluxo produtivo e o volume dos estoques (Shambu e Suresh, 2000; Aljuneidi e Bulgak, 2016). Estudos relatados por Miltenburg (2001) e Kucukkoc e Zhang (2015) mostram resultados consideráveis quanto melhoras no desempenho de produção, redução do espaço físico e diminuição nos defeitos das peças.

A configuração celular favorece a separação dos processos de fabricação em grupo de famílias de peças ou produtos, desta forma, conforme Yoshino (2008) essas peças se movimentam no meio da produção de acordo com o critério de agrupamento. Neste sentido Lorini (1993) e Black (1998) defendem a formação de famílias de peças conforme tamanho e geometrias similares onde a sequência de etapas de produção definiria a organização da célula. Entretanto, Contador (1991) salienta que a definição de famílias de peças somente 
pela geometria, pode ser induzida ao erro, pois se deve levar em consideração a similaridade na sequência das etapas de processo. Segundo Silveira (1994) devem ser considerados três elementos básicos para implantação da tecnologia de grupos, elemento materiais, elemento máquinas e elemento pessoas. Os materiais indicam o método de formação da família, as máquinas são definidas conforme as características de peças processadas e as pessoas são responsáveis pela organização, controle e manutenção da célula.

\section{MÉTODO DE PESQUISA}

Este trabalho apresenta o estudo e a proposição de um novo layout de um setor de montagem e acabamento de peças em compósitos por meio da redução das movimentações e otimização do ambiente de trabalho usando a tecnologia de grupos e o arranjo celular para a implementação. Para tanto foram seguidos os seguintes passos:

- Analise do layout atual através da observação do fluxo produtivo, identificando oportunidades de melhorias;

- Identificação de um conjunto de peças para estudo e propor ao setor um layout adequado, com base no estudo das diferentes características de arranjos físicos;

- Visualização das características das famílias de peças por processo ou produto;

- Criação de uma célula experimental de produção;

- Avaliação dos tempos e movimentações para a célula desenvolvida;

- Divulgação dos resultados obtidos com a implementação do layout proposto.

O trabalho foi realizado dentro de uma abordagem qualitativa, exploratória e descritiva, utilizando-se da técnica de pesquisa-ação.

O estudo foi desenvolvido no setor de montagem e acabamento de peças em compósitos, em uma unidade que integra empresa montadora de carrocerias para ônibus, situada em Caxias do Sul, RS, onde produz peças e componentes cujo material base é a fibra de vidro, resina poliéster e outros materiais poliméricos. Os componentes são produzidos por processos de RTM (Resin Transfer Molding), laminação ou compressão em seguida são direcionadas a área de acabamento para eliminação de imperfeições da superfície e montagem de componentes complementares através de adesivos ou fixação mecânica.

O setor responsável pela montagem e acabamento conta com 154 colaboradores onde são produzidas cerca de 6,360 peças mensalmente para atender a linha de montagem e outras unidades da corporação. Em função da complexidade na alteração total do setor foi elencada uma área piloto para implementação do layout proposto. Desta forma é possível analisar os resultados esperados e disseminar os conceitos.

Para Matheus (2010) a etapa de acabamento e montagem em peças produzidas com núcleo em fibra de vidro é realizada para suprir limitações no processo de fabricação em virtude das características e complexidades na geometria da peça. A segmentação do molde através de postiços é comum tanto para a produção em RTM como para laminação ou compressão. Este fator ocasiona marcas nas regiões de união onde são desempenhadas as atividades de acabamento.

\section{Técnicas e Procedimentos Adotados}

Conforme Silveira (1999), no desenvolvimento de um layout é importante haver a participação dos operadores no sentido de agregar sugestões para a melhoria permanente da organização 
do trabalho e do controle nos processos devido a dinâmica na alteração do sistema. Sendo assim como ponto inicial dos trabalhos a gestão operacional comparecem as reuniões para expor às dificuldades e proporcionar apoio às etapas de avaliação e implementação.

Para a evolução dos estudos foi necessário analisar o layout atual e identificar as oportunidades de melhorias para elaboração da proposta com o intuito de atingir os objetivos esperados. Segundo Silveira (1999) o projeto de layout para células de manufatura pode ser executado obedecendo três fases: Apresentação, Aplicação e Avaliação (Tabela 1).

O levantamento das informações pertinentes a área proposta para alteração tem grande importância, pois se faz necessário estabelecer padrões de tempo para o trabalho realizado com o intuito de criar parâmetros no dimensionamento dos recursos e espaços utilizados. A programação das atividades e a capacidade produtiva são fatores vinculados ao controle dos tempos envolvidos no processo (Chase et al., 2006).

Neste estudo foram verificados os tempos de processo para a fabricação dos modelos de peças através de cronoanálises. Tais tempos foram convertidos em padrões de mão-deobra que são expressos em minutos por unidade de produção para a operação (Gaither e Frazier, 2007). A aquisição dos tempos de operação foi efetuada conforme a ferramenta de worksampling, desta forma foi possível verificar os tempos reais de ocupação dos colaboradores na fabricação das peças e os tempos utilizados em atividades que não agregam valor a peça. Este método de análise é fundamental para identificar as oportunidades de melhorias e observar de maneira ampla as etapas de operações (Greene e Lee, 2009).

Tabela 1. Fases de implementação para alteração de layout

\begin{tabular}{|c|c|c|}
\hline $\mathbf{1}^{\mathbf{a}}$ Fase & $\mathbf{2}^{\mathbf{a}}$ Fase & $\mathbf{3}^{\mathbf{a}}$ Fase \\
\hline APRESENTAÇÃO & APLICAÇÃO & AVALIAÇÃO \\
\hline Definições dos Objetivos & Formação do layout & $\begin{array}{c}\text { Análise do arranjo atual e } \\
\text { proposto }\end{array}$ \\
\hline Característica do layout atual & Formação das Famílias & Desempenho operacional \\
\hline Levantamento de dados & $\begin{array}{c}\text { Treinamento aos } \\
\text { envolvidos }\end{array}$ & Resultados do layout proposto \\
\hline
\end{tabular}

Durante a formação das famílias de peça, levou-se em consideração as características dimensionais, os roteiros de processos envolvidos para cada modelo e a similaridade nas operações executadas. Desta forma foi possível distinguir e direcionar o espaço físico para a organização da produção, bem como o modelo de layout mais adequado. Com base na identificação das famílias de peças produzidas e com o estudo das características da organização em células, optou-se em implementar um projeto piloto estipulando uma área para a introdução de uma célula em "U".

Para o sucesso da célula piloto é fundamental o acompanhamento da gestão e das áreas auxiliares para os operadores possuam metas claras e ferramentas de controle da produção visual com o intuito de direcionar o planejamento e a programação das atividades (Olorunniwo e Udo, 2002; Singh e Singh, 2014). Dalmas (2004) complementa a utilização do treinamento como ferramenta para encorajar a operação de múltiplas tarefas e ocasionar flexibilidade no sistema consequentemente eliminar os gargalos na célula. 
$\mathrm{Na}$ fase de avaliação observam-se os retornos relativos às técnicas adotadas na implementação, além do comprometimento das pessoas na melhoria do processo instalado e autonomia na comunicação e disseminação da informação. O controle nos estoques em processo e o aumento da qualidade nos produtos são fatores esperados nesta etapa.

Em função das dimensões e da complexidade na alteração de toda área responsável pela produção dos componentes em estudo, optou-se pelo projeto de área piloto com a família de escadas, onde foram realizados os testes e ajustes para propagação em todo layout conforme as características das peças destacadas pela tecnologia de grupos. Para Slack et al. (2009), a execução de áreas pilotos serve de base para avaliar o modelo adotado, desta forma reduzir os riscos de falhas e evitar investimentos desnecessários.

\section{DESENVOLVIMENTO DO ESTUDO}

\section{Análise do arranjo físico atual}

$\mathrm{Na}$ organização atual, as peças são processadas em estações de trabalho fixas onde se realizam todas as atividades de produção. Os componentes de montagem estão localizados distantes do local de montagem o que eleva as perdas por movimentação. Os adesivos e materiais utilizados na montagem e acabamento estão localizados em uma central desta forma, todos os colaboradores gastam o tempo produtivo para dirigir-se até esta central e coletar material para cada peça produzida. Os materiais (adesivos e resinas) empregados na montagem possuem um período para polimerização limitado. Assim, caso seja coletado material além da quantidade correta de aplicação e caso não seja aplicado na peça dentro do período ocorre o descarte do material. Somado a isso, os perfis metálicos de algumas peças, como por exemplo, dos degraus das escadas, recebem ajustes durante a montagem para se enquadrarem a geometria da peça produzida, caracterizando uma perda por retrabalho. A inspeção na qualidade das peças é um aspecto dificultado pela carência de sequência produtiva, sendo realizado o acabamento em peças que são consideradas prioridades em relação ao seu prazo, enquanto outras peças persistem um tempo demasiado na área de trabalho sem agregação de tarefas. Deste modo os colaboradores estão sujeitos a aplicar operações de acabamento com redundância sem necessidade, elevando o custo operacional da peça.

As peças a serem processadas nesse setor, estão armazenadas a uma distância de $97 \mathrm{~m}$ do layout atual para montagem e acabamento de escadas. Desta forma, esta distância é sempre percorrida para o transporte e abastecimento do posto de operação. Após a peça estar concluída é preciso conduzi-las mais $70 \mathrm{~m}$ para o almoxarifado central onde serão posteriormente direcionadas para a linha de montagem do ônibus.

Em função das dificuldades encontradas no processamento e da funcionalidade do layout (por processo) atual é possível observar um elevado estoque intermediário entre as operações. As deficiências na programação de produção interferem no planejamento logístico para fornecimento de peças, estes fatores elevam os tempos com espera de componentes ou ate mesmo a necessidade de adaptações nos componentes existentes para montagem.

As características no layout atual dificultam o controle e o fluxo produtivo com consequente ociosidade na ocupação dos espaços físicos disponíveis. Na figura 2 é possível observar a distribuição das peças e recursos no layout atual. 


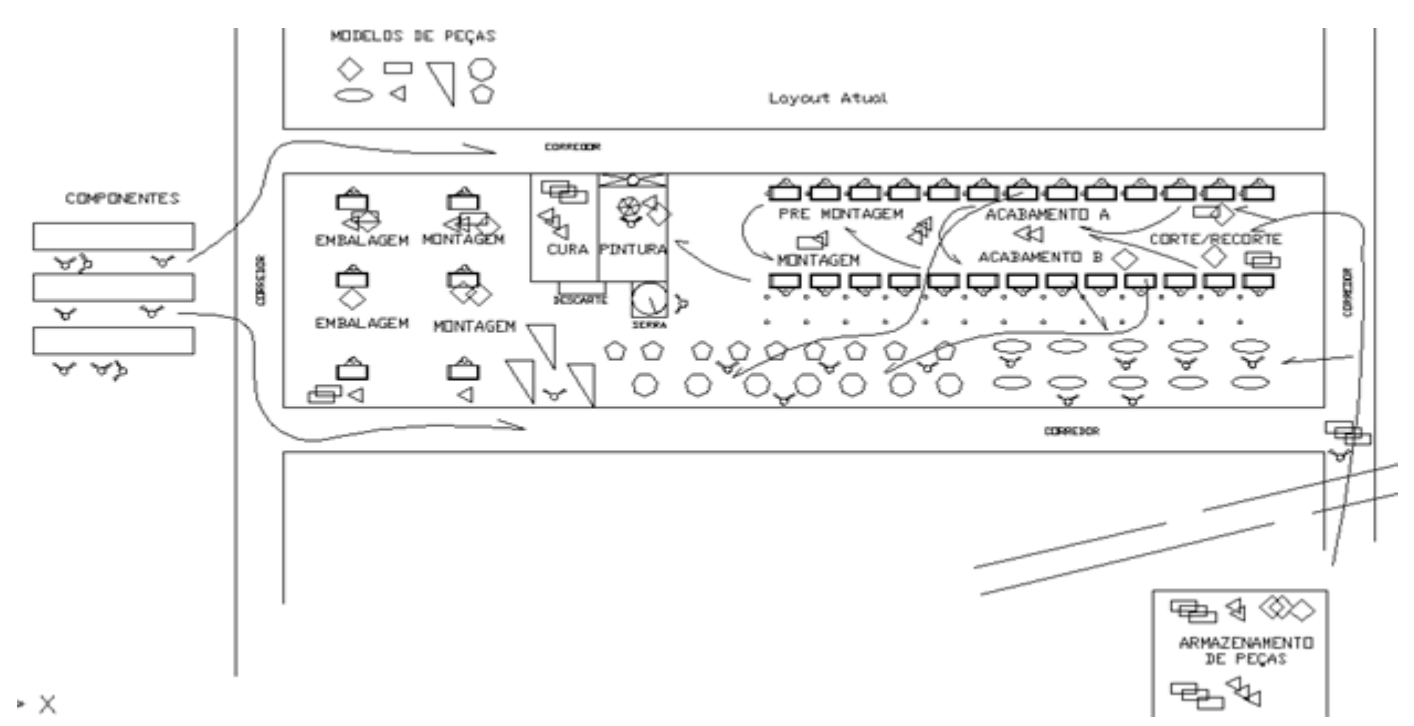

Figura 2. Distribuição do layout atual e fluxo de materiais

Através da análise do layout atual é proposto uma organização fundamentada em células de manufatura através da formação em famílias de partes com objetivo de reduzir os estoques intermediários criar fluxo na produção e trabalhar conforme programação pré-estabelecida. No primeiro momento as peças continuariam a vir do armazenamento referente à etapa anterior após a evolução da alteração o propósito é reduzir os estoques do processo anterior e direcionar as peças ao setor de montagem e acabamento.

\section{Arranjo físico proposto}

No modelo proposto os componentes são inseridos ao lado das operações para atender as demandas de peças produzidas, onde o acionamento acontece por cartões kanban, sendo assim há redução das movimentações dos colaboradores e dos estoques de componentes. As etapas de processo são realizadas no interior da célula, neste sentido as famílias de peça são dimensionadas conforme demanda e capacidade de produção. Na figura 3 é possível verificar a proposta de alteração para toda a área de acabamento e montagem.

Para alteração do layout proposto é sugerido à implementação de sistema para abastecimento de componentes e peças através da programação diária de produção com a utilização de movimentador logístico, assim evitando a dispersão dos colaboradores responsáveis pela atuação nas células de produção. 


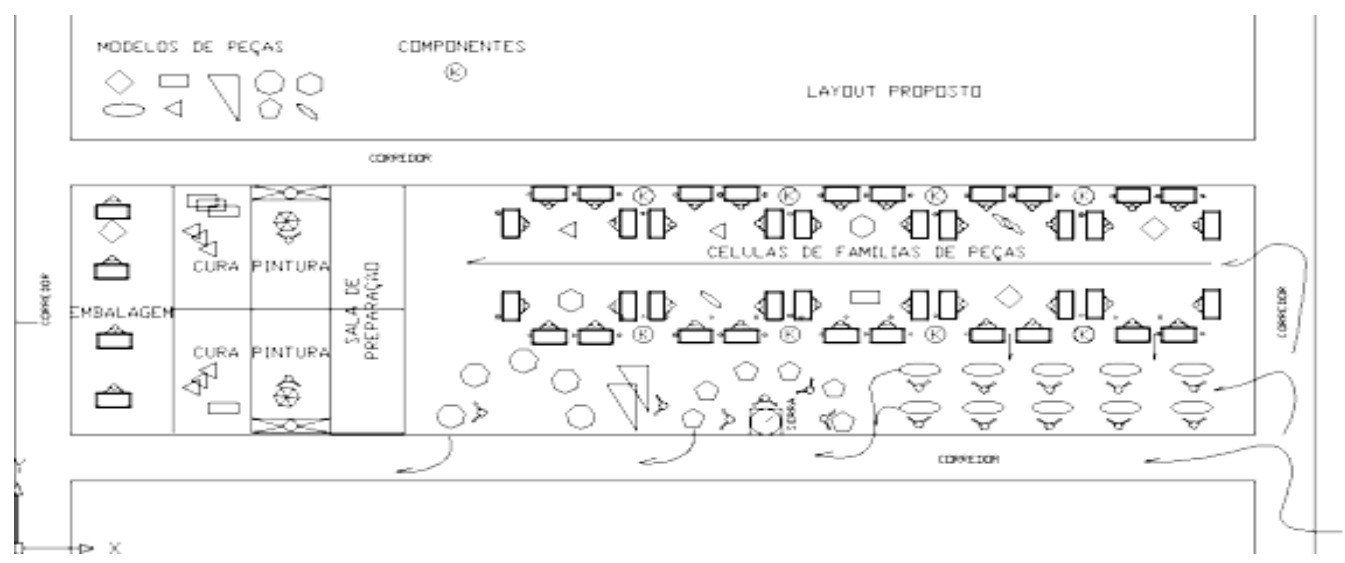

Figura 3. Organização geral do layout proposto

\section{Estudo para implementação celular}

A implementação da célula piloto para escadas foi realizada no período de 27 de julho a 17 de setembro, com o envolvimento e cumprimento de prazos por todas as áreas responsáveis como produção, logística, engenharia, segurança e qualidade.

A área ocupada para realização das tarefas referentes a família de escada possui $54 \mathrm{~m}^{2}$ onde atualmente estão alocados 12 colaboradores nos dois turnos com total de 17,6 horas disponíveis. Para suprir a demanda de 42 peças, o colaborador responsável pela primeira tarefa de montagem percorre cerca de $2 \mathrm{~km}$ diários até a atividade anterior para direcionar as peças para produção solicitada no espaço atual.

Com o acompanhamento produtivo durante 8 dias foi possível definir o nível de utilização da mão de obra eficiente e identificar as causas geradoras de perdas no processo, originadas pelas características atuais do arranjo físico e distribuição das peças e recursos. Assim sendo, identifica-se as oportunidades de melhorias nos recursos atuais além de corrigir as tarefas e procedimentos que são realizadas sem necessidade.

A tabela 2 demonstra as informações adquiridas no acompanhamento de produção.

Tabela 2. Acompanhamento da produção com layout atual

\begin{tabular}{|c|c|c|c|c|c|c|c|c|c||}
\hline \multicolumn{10}{|c|}{ Processo Atual de Produção } \\
\hline \hline \multicolumn{2}{|c|}{ Tempo disponível (horas) } & $\mathbf{8 , 8}$ & Total de Colaboradores & $\mathbf{1 2}$ & Período Acompanhamentd & \multicolumn{2}{c|}{ 8 dias - 2 turnos } \\
\hline \hline Tempo (min) & $\mathbf{2 4 / 0 7 / 2 0 1 2}$ & $\mathbf{2 5 / 0 7 / 2 0 1 2}$ & $\mathbf{2 6 / 0 7 / 2 0 1 2}$ & $\mathbf{2 7 / 0 7 / 2 0 1 2}$ & $\mathbf{3 0 / 0 7 / 2 0 1 2}$ & $\mathbf{3 1 / 0 7 / 2 0 1 2}$ & $\mathbf{0 1 / 0 8 / 2 0 1 2}$ & $\mathbf{0 2 / 0 8 / 2 0 1 2}$ & TOTAL \\
\hline \hline Disponiveis & 6.336 & 6.336 & 6.336 & 6.336 & 6.336 & 6.336 & 6.336 & 6.336 & 50.688 \\
\hline Produtivas & 4.311 & 4.000 & 5.620 & 3.838 & 4.876 & 5.735 & 4.961 & 4.794 & 38.135 \\
\hline Eficência & $68,04 \%$ & $63,13 \%$ & $88,70 \%$ & $60,58 \%$ & $76,95 \%$ & $90,52 \%$ & $78,30 \%$ & $75,66 \%$ & $75,24 \%$ \\
\hline Peças Produzidas & 39 & 49 & 47 & 37 & 41 & 45 & 37 & 41 & 42 \\
\hline Tempo médio/peça & 111,97 & 82,48 & 120,86 & 105,16 & 120,39 & 128,88 & 135,91 & 118,37 & 115,50 \\
\hline
\end{tabular}

Dentre as atividades executadas no posto de montagem e acabamento de escadas são a instalação de reforços, isolamento acústico inferior, montagem de perfis e acabamento nas regiões danificadas, além de pintura, transporte e embalagem das peças. Conforme a figura 4 é possível identificar o elevado percurso realizado para corte dos perfis na serra e grande 
quantidade de peças em processo. Os materiais empregados na montagem, como massas e adesivos, estão localizadas numa central a $13 \mathrm{~m}$ do posto de aplicação.

Com o objetivo de solucionar as dificuldades encontradas no layout atual foi desenvolvido a implementação de célula em forma de "U", neste sentido propor condições de trabalho e reduzir as perdas identificadas no processo. Para o agrupamento da família de peças levouse em consideração as características geométricas das peças e a similaridade nos processos empregados durante a manufatura. O espaço de instalação está com uma área de $40 \mathrm{~m}^{2}$, onde foram instaladas melhorias para reduzir o tempo de processo e evitar a movimentação dos colaboradores, no sentido de evitar a saída do posto de trabalho e não haver circulação de pessoas dentro da célula para abastecimento de material.

Os materiais como manta de isolamento acústico, perfis, parafusos são abastecidos pela logística conforme programação de produção, enquanto os componentes que integram o produto e precisam ser montados são dispostos em prateleiras especificas e fornecidos pela logística através de acionamento de cartões kanban em caixas padronizados, retornáveis e manuseáveis pela força de uma pessoa. Desta forma os materiais e ferramentas estão próximos ao posto de trabalho dispensando os operadores a fazer estas tarefas que não agregam diretamente valor ao produto.

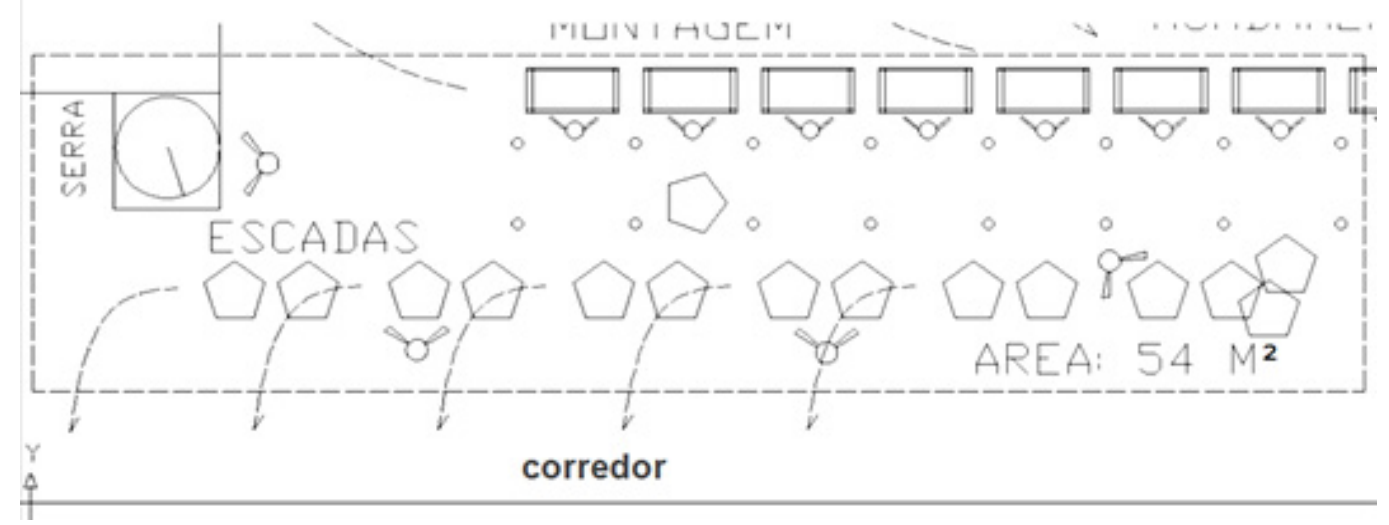

Figura 4. Detalhe do posto atual para montagem e acabamento de escadas

O treinamento dos colaboradores auxilia para melhorar o desempenho operacional e a qualidade dos serviços tanto no acabamento e pintura, somente das regiões necessárias, como na operação da serra para aferição dos ângulos nos perfis montados. A manutenção da limpeza na célula foi auxiliada pela utilização de ferramentas com aspiração, assim evitando a propagação das poeiras geradas pelo acabamento. Na figura 5 observa-se a proximidade dos recursos, por exemplo, a serra e materiais como adesivos no interior da organização implementada para célula piloto de montagem e acabamento de escadas.

Para o balanceamento das operações foram identificadas as seguintes tarefas executadas na célula: Montagem Reforço/Isolamentos (A), Montagem perfis da escada (B), Acabamento (C, D, E), Pintar (F), Embalar (G) e Transportar (H). 


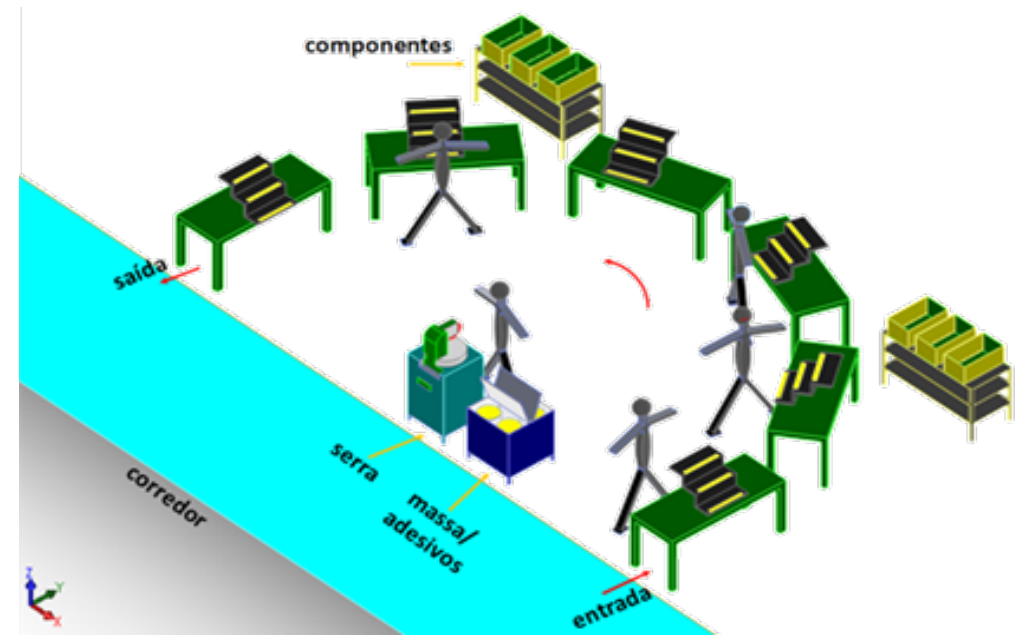

Figura 5. Arranjo celular implementado para montagem e acabamento de escadas

Pela análise de 38 modelos diferentes na mesma família de peças das escadas encontrouse uma média diária de produção em 42 peças, com tempo médio de 110,86 minutos por unidade produzida. Sendo 17,6 horas disponíveis é necessário produzir 2,42 unidades por hora para suprir a demanda, assim o tempo de ciclo é de 24,79 minutos. A equação (1) (Slack, 2009) demonstra o cálculo do tempo de ciclo.

$$
\text { Tempo_de_ciclo }=\frac{\text { Tempo_disponivel }}{\text { Demanda }}=24,79 \min \text { por } \_ \text {peça }
$$

Considerando tempo médio por peça e um tempo de ciclo de 24,79 podemos calcular através da equação (2) (Slack, 2009) o número mínimo de estações.

$$
\text { Numero_de_estações }=\frac{\sum \text { tempos_individuais }}{\text { Tempo_de_ciclo }}=4,47 \text { estações }
$$

Encontra-se um número mínimo de estações em 4,47 estações de trabalho. Entretanto este cálculo é teórico, sendo na prática arredondado para 5 estações de trabalho. Na tabela 3 representam-se as tarefas em relação aos centros de trabalho onde a somatória do tempo em cada estação é inferior ao tempo de ciclo.

Tabela 3. Balanceamento dos tempos de operação nos centros de trabalho

\begin{tabular}{|ccccccc|}
\hline Tarefas em centros de trabalho & A & B & C, F & D, G & E, H \\
\hline Centros de trabalho & 1 & 2 & 3 & 4 & 5 \\
\hline $\begin{array}{c}\text { Tempo total em cada estação de trabalho } \\
\text { (min.) }\end{array}$ & 21,44 & 21,44 & 22,67 & 22,24 & 23,07 \\
\hline
\end{tabular}


os centros de trabalho, a capacitação dos operadores e a filosofia do trabalho polivalente são fundamentais para o sucesso e continuidade da célula de produção, pois os colaboradores serão responsáveis pela execução de mais de uma tarefa dentro do layout proposto.

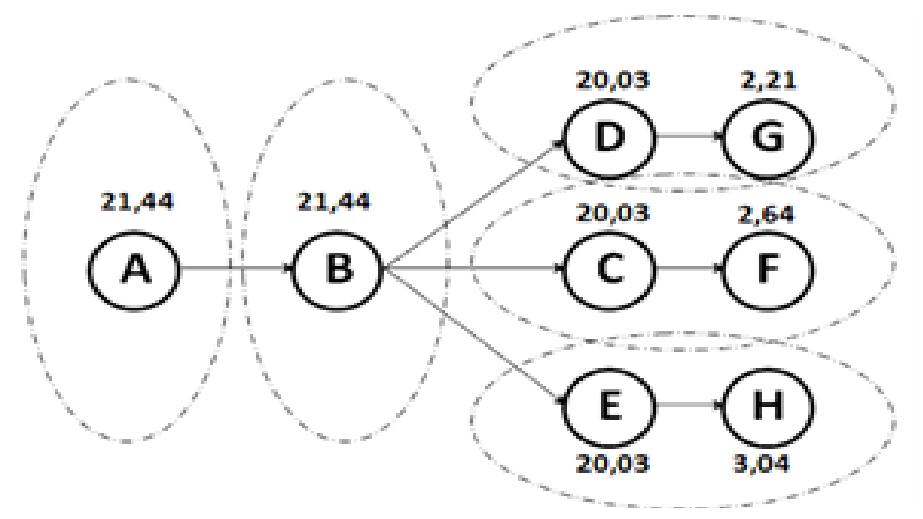

Figura 6. Diagrama de precedência para agrupamento de atividades

Após a implementação da célula e das melhorias realizadas nos recursos para montagem e acabamento foi possível observar uma melhora na eficiência produtiva, embora ser uma elevação apenas de $2,41 \%$ este valor tende aumentar com a consolidação dos princípios da manufatura celular. Apesar de manter a demanda de peças foi possível reduzir o quadro funcional em duas pessoas que puderam ser direcionadas para suprir necessidades em outras áreas. Na tabela 4 pode-se observar o detalhamento das informações no período de observação.

Tabela 4. Acompanhamento da produção após implementação da célula

\begin{tabular}{|c|c|c|c|c|c|c|c|c|c|}
\hline \multicolumn{8}{|c|}{ Implementação do Layout Proposto } \\
\hline \hline \multicolumn{2}{|c|}{ Tempo disponível (horas) } & $\mathbf{8 , 8}$ & Total de Colaboradores & $\mathbf{1 0}$ & Período Acompanhamentd & \multicolumn{2}{|c|}{$\mathbf{8}$ dias - 2 turnos } \\
\hline \hline Tempo (min) & $\mathbf{2 7 / 0 8 / 2 0 1 2}$ & $\mathbf{2 8 / 0 8 / 2 0 1 2}$ & $\mathbf{2 9 / 0 8 / 2 0 1 2}$ & $\mathbf{3 0 / 0 8 / 2 0 1 2}$ & $\mathbf{3 1 / 0 8 / 2 0 1 2}$ & $\mathbf{0 3 / 0 9 / 2 0 1 2}$ & $\mathbf{0 4 / 0 9 / 2 0 1 2}$ & $\mathbf{0 5 / 0 9 / 2 0 1 2}$ & TOTAL \\
\hline \hline Disponiveis & 5.280 & 5.280 & 5.280 & 5.280 & 5.280 & 5.280 & 5.280 & 5.280 & 42.240 \\
\hline Produtivas & 3.707 & 3.440 & 4.833 & 3.301 & 4.193 & 4.932 & 4.266 & 4.123 & 32.796 \\
\hline Eficência & $70,22 \%$ & $65,15 \%$ & $91,54 \%$ & $62,52 \%$ & $79,42 \%$ & $93,41 \%$ & $80,80 \%$ & $78,08 \%$ & $77,64 \%$ \\
\hline Peças Produzidas & 38 & 46 & 43 & 39 & 44 & 45 & 35 & 43 & 42 \\
\hline Tempo médio/peça & 97,57 & 74,79 & 112,40 & 84,64 & 95,30 & 110,84 & 121,89 & 95,88 & 99,16 \\
\hline \hline
\end{tabular}

\section{ANÁLISE E INTREPRETAÇÃO DOS RESULTADOS}

Com a implementação do arranjo proposto observam-se mudanças favoráveis no desempenho produtivo, mesmo com as constantes oportunidades no aperfeiçoamento do processo. $\mathrm{O}$ controle e a facilidade na gestão das pessoas são evidentes, pois o espaço de atuação de cada tarefa é definido de maneira com que os gargalos e as prioridades são visíveis no fluxo de produção.

Através dos aperfeiçoamentos implementados foi possível reduzir o tempo de produção dos componentes e as movimentações geradoras de perdas no processo, entretanto a demanda de produção e o tempo de ciclo se mantiveram. Desta forma foi possível dimensionar o quadro funcional somente para a mão de obra suficiente no atendimento das necessidades e otimizar o espaço físico de acordo com as características da formação do layout. As principais 
alterações referentes aos recursos materiais, humanos e métodos de trabalho analisados no layout anterior ao atual implementado estão relacionadas (Tabela 5).

Ao comparar o worksampling anterior ao realizado após a implementação da célula, podese observar uma elevação no aproveitamento da mão de obra em $2,41 \%$ para trabalhos produtivos que incorporam valor as peças fabricadas. Em contrapartida as operações de movimentação e ociosidades tendem a diminuir na medida em que os conceitos da manufatura celular são absorvidos pelo sistema de produção implantado.

Tabela 5. Análise de características nos layouts

\begin{tabular}{||l|l|l||}
\hline \multicolumn{1}{|c|}{ Descrição } & \multicolumn{1}{c|}{ Anterior - Funcional } & \multicolumn{1}{c||}{ Atual - Célula } \\
\hline \hline Programação & Ordem de Produção & Ordem de Produção e Kanban \\
\hline Formato & Linear & "U" \\
\hline Qtde de operadores & Fixo & Variável \\
\hline Capacidade de produção & Fixo & Variável \\
\hline Capacitação dos operadores & Especializado & Polivalente \\
\hline Abastecimento de materiais & Realizado pelo operador, a pé & Realizado pelo abastecedor com o pequeno trem \\
\hline Posição dos recursos (máquinas) & Próximo ao armazenamento do material & Próximo ao local de utilização dos componentes \\
\hline Tempo entre postos de trabalho & Desbalaceado & Equilibrado \\
\hline Quantidade de peças entre postos & Várias & Uma \\
\hline Disposição de materiais & Distantes & Ao lado do posto de trabalho \\
\hline Disposição de componentes & Em cima da bancada, no chão, má ergonomia & No abastecedor frontal, boa ergonomia \\
\hline
\end{tabular}

O trabalho para acompanhamento de aproveitamento operacional foi executado em 3 dias durante o primeiro turno com observação de 3 colaboradores, neste período foram registradas as atividades exercidas nas 8,8 horas disponíveis. Pela análise da figura 7 as atividades de pré-montagem, montagem e corte possui uma elevação no tempo decorrente da redução das movimentações externa e interna, porém na atividade de acabamento houve uma redução no tempo de atuação em virtude do estabelecimento dos pontos específicos de atuação na peça.

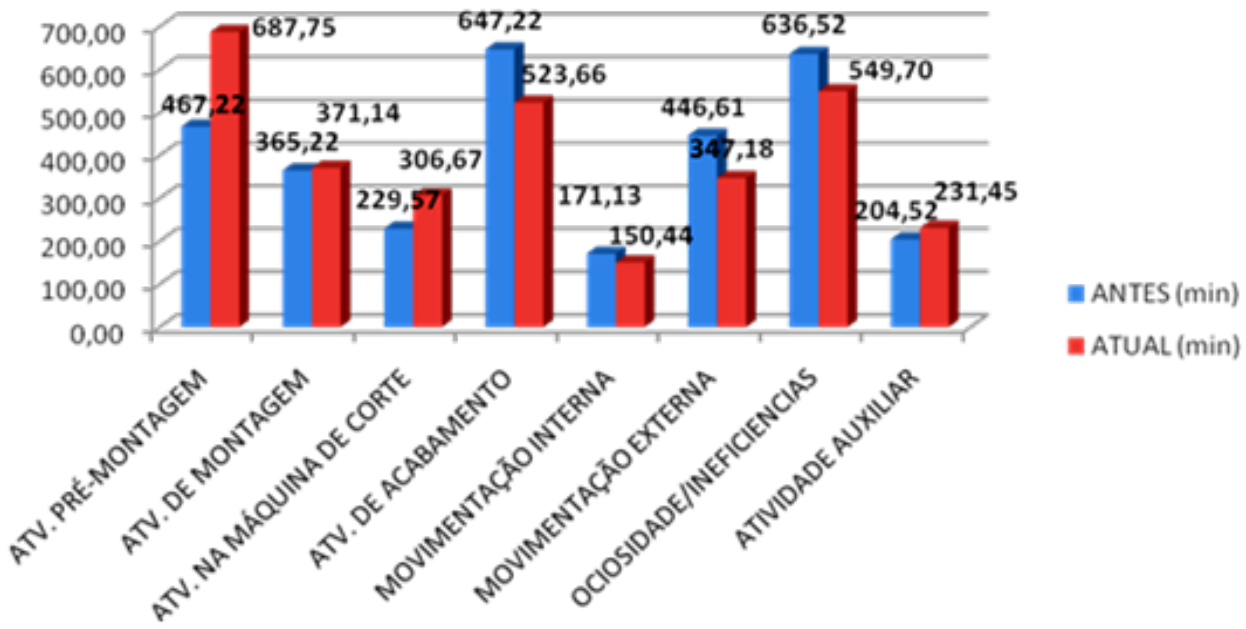

Figura 7. Análise de aproveitamento operacional após desenvolvimento da alteração 
A alteração do arranjo físico e a implantação de prateleiras para armazenamento de componentes próximos as atividades, reduziu 500 metros diários em movimentações antes realizadas pelo posto de montagem. Caso seja implantada a proposta de abastecimento da célula através de carrinho movimentador pela logística conforme programação diária, os ganhos com redução na movimentação podem ser projetados para 1,47 km diários pela analise somente das peças produzidas pela célula de escadas.

A aproximação dos componentes, treinamentos aos colaboradores, definição de processos e o aperfeiçoamento dos recursos aplicados as tarefas propiciaram uma redução média de $14 \%$ nos tempos de operação. Após o balanceamento das operações e definição dos tempos de ciclo, foi possível atender a demanda de 42 escadas diárias com a redução de 2 colaboradores que puderam ser realocados para atuar em outras atividades da empresa. Pela ocupação do espaço físico evidencia-se uma área anterior de $53 \mathrm{~m}^{2}$ onde existiam 12 postos de trabalho, sendo $40 \mathrm{~m}^{2}$ no layout atual onde foram balanceados 5 postos de trabalho. Desta forma, considerando um número mínimo de estações em 4,47 postos, o sistema de produção de escadas migrou de um layout funcional com 37,27\% para um layout celular com $89,44 \%$ de aproveitamento, além de uma redução de $24,53 \%$ do espaço físico anterior.

\section{CONCLUSÃO}

Em virtude da necessidade em aprimorar o fluxo de materiais e pessoas, adquirir um melhor aproveitamento do espaço físico com redução de estoques intermediários de peças e componentes foi proposto à alteração do arranjo físico atual para a manufatura celular. $O$ processo de alteração mostrou-se um aprendizado amplo para todas as áreas de atuação onde o trabalho em equipe e a motivação individual foram essenciais para atingir os resultados. A redução nos tempos em processo, ociosidades e estoques intermediários tornam a empresa competitiva e melhoram o atendimento aos clientes quanto aos prazos de entrega e qualidade. O sistema de produção pela manufatura celular através da utilização da ferramenta tecnologia de grupos possibilitou a distinção das famílias de peças pela similaridade das formas geométricas e processos aplicados.

A melhoria gradual do layout por meio da utilização da metodologia proposta deve ser aplicada como ferramenta de monitoramento, atualização e aperfeiçoamento do layout implementado, pois são constantes as alterações nos produtos fabricados.

A implantação proposta resultou em ganhos reais expressivos como por exemplo: redução de $24 \%$ do espaço físico, redução média de $14 \%$ nos tempos de operação e melhora no aproveitamento da mão de obra em $2,4 \%$ em trabalhos que incorporam valor as peças fabricadas.

Do ponto de vista acadêmico, sugere-se o desenvolvimento da metodologia com técnicas mais sofisticadas para formação das famílias de partes através da análise via simulação computacional além da atual distinção visual por similaridades geométricas.

Com a implantação da proposta de células de manufatura em todas as famílias de peças é possível reduzir consideravelmente a área física ocupada pelo setor atual, visto que inúmeras atividades realizadas nos processos de acabamento foram identificadas como déficits de processos anteriores. A implantação da célula revelou oportunidades de melhorias 
não somente no setor analisado, mas em todas as áreas anteriores responsáveis pelo fornecimento de peças, desta forma o setor tende a tornar-se um posto mais voltado à montagem do que ao acabamento de peças no contexto da empresa.

\section{REFERÊNCIAS BIBLIOGRÁFICAS}

Aljuneidi, T. and Bulgak, A.A. A mathematical model for designing reconfigurable cellular hybrid manufacturing-remanufacturing systems. Int J Adv Manuf Technol, 2016, 87, 1585-1596.

ANTUNES Jr., JAV. Sistemas de produção. Conceitos e práticas para projeto e gestão da produção enxuta. Porto Alegre: Bookman, 2008.

ARRUDA, P.E. Levantamento do Estágio de implantação da tecnologia de Grupo e Células de Manufatura no Estado de São Paulo. Tese de Doutorado, USP, 1994.

ASKIN, R.G. and GOLDBERG, J.B. Desing and Analysis of Lean Production Systems. New York: John Wiley \& Sons Ins., 2002.

BLACK, J.T. Projeto da fábrica com futuro. Porto Alegre, Editora Bookman, 2001.

CONCEIÇÃO, V.S. Otimização do fluxo de materiais através da manufatura celular. Revista Produção, v. 15, n. 2, p. 235-250, Maio/Ago. 2005.

CONTADOR, J.C. Células de Manufatura, Departamento de Enga de Produção da Faculdade de Engenharia da UNESP. 1991.

CURY, A. Organização e Métodos. São Paulo: Atlas, 2000.

DALMAS, V. Avaliação de um layout celular implementado: um estudo de caso em uma indústria de autopeças, Porto Alegre 2004.

GAITHER, N.; FRAZIER, G. Administração da produção e operações. 8. ed. São Paulo: Pioneira Thomson Learning, 2007.

GREENE, J.; LEE, N. Work Sampling: A Method for Assessing and Monitoring Productivity. The Business Owner. 2009.

KUCUKKOC, I.; ZHANG, D.Z. Balancing of parallel U-shaped assembly lines. Computers \& Operations Research, 2015, 64, 233-244.

LEITE, R.L. and DINIZ, A.M.F. Estudo do arranjo físico: o caso do gargalo de produção na manufatura de máquinas de costura. Simpósio de engenharia de produção, 2006, Bauru. URCA, 2006.

MATHEUS, M.A. Fiberglass Aprenda Fibra de Vidro. Editora Viena, 2010.

MILTENBURG, J. U-shaped production lines: A review of theory and practice. International Journal of Production Economics, 2001, 70(3), 201-214.

OLIVEIRA, Djalma de Pinho Rebouças de. Administração de processos: conceitos, 
metodologia, práticas. 2. ed. São Paulo: Atlas, 2007.

OLIVÉRIO, J.L. Projeto de fábrica: produtos, processos e instalações industriais. São Paulo: IBLC. 1985.

OLORUNNIWO, F., UDO, G. The impact of management and employess on cellular manufacturing implementation. International Journal of Production Economics, 2002, 76.

OSBAYRAK, M.; BELL, R. A knowledge-based decision support system for the management of parts and tools in FMS. Decision Support Systems, 2003, 35(4), 487-515

SECCHI, R. and CAMUFFO, A. Rolling out lean production systems: a knowledgebased perspective, International Journal of Operations \& Production Management, 2016, 36(1), 6185.

SHAMBU, G. and SURESH, N. C. Performance of hibrid cellular manufacturing systems: A computer simulation investigation. European Journal of Operational Research, 2000, 120(2), 436-458

SINGH, A. and SINGH, H. Implementation of a Cellular Manufacturing Tool for Minimization of Non Value Added Activities Int. Journal of Engineering Research and Applications, 2014, 4(8), 97-103,

SLACK, N., CHAMBERS, S. and JOHNSTON, R. Administração da produção. 2. ed. São Paulo: Atlas, 2009.

SMEDS, R. Managing Change towards Lean Enterprises. International Journal of Operations \& Production Management. University Press, 1994.

URNAU, E. and DOMINGUES, M.S. Flexibilidade na Produção: Implantação de células de manufatura em uma empresa de confecções. Revista de Negócios. Volume $1 n^{\circ} 3$ abr/junho, 1996.

VILLAR, A de Melo. and NÓBREGA JR, CL. Planejamento das Instalações Industriais. João Pessoa: Manufatura, 2004.

YASUDA, K. and YIN, Y. Dissimilarity measure for solving the cell formation problem in cellular manufacturing. Computers \& Industrial Engineering, 2001, 39(1-2), 1-17.

YOSHINO, R.T. Proposta de um sistema de produção enxuta para o segmento calçadista. 315 f. Tese (Doutorado em Engenharia de Produção) - Escola de Engenharia de São Carlos da Universidade de São Paulo- USP, São Carlos, 2008. 